\title{
The Influence of Access to Facilities on the Physical Activity Level of High School Pupils in Bophelong, a Semi-Urban Area of South Africa
}

\section{$L$ van den Berg}

\author{
North-West University, Faculty of Economic Sciences and Information \\ Technology, PO Box 1174, Vanderbijlpark, 1900 \\ Email: liandi.vandenberg@nwu.ac.za \\ W.C.J. Grobler \\ North-West University, Faculty of Economic Sciences and Information \\ Technology, PO Box 1174, Vanderbijlpark, 1900 \\ Email: wynand.grobler@nwu.ac.za
}

\section{Doi:10.5901/mjss.2014.v5n23p905}

\begin{abstract}
Physical activity levels among adolescents decline during their teenage years and into early adulthood. Socio-economic background plays an important role in adolescents' physical activity, as children from rural communities participate less regularly in physical activities due to a lack of access to facilities, the cost of programmes and in general due to limited facilities. The focus of public health researchers has shifted from individual motivational theories on the participation in physical activity to the ecological theory, which includes the effects of community environments on health matters. Significant differences prevail in physical activity participation patterns in various geographical areas and different demographic groups. Consequently, the purpose of this study was to assess the access to facilities in a semi-urban area and the physical activity levels of high school pupils. 155 high school pupils from Bophelong, a semi-urban area in the Gauteng province, voluntarily and anonymously completed questionnaires regarding their physical activity participation, accessibility of stores, recreational facilities and other important structures within their neighbourhood. Results indicated that pupils from a low socio-economic community had limited access to facilities such as parks, recreation centres, gymnasia and fitness centres, which are known to induce physical activity. Pupils actively commuted considerable distances daily to and from school, contributing substantially to their overall physical activity. Participation of the minority in school sport was evident, but apart from walking and inadequate school sport participation, few opportunities existed for adolescents from this semi-urban high school to engage in moderate recreational physical activities.
\end{abstract}

Keywords: Physical activity; accessibility; facilities; semi-urban area.

\section{Introduction}

Regular physical activity is important for the maintenance and enhancement of general health such as the improvement of psychological health, the maintenance of healthy bones, muscles and joints, and is a contributing factor of weight control (Pate et al., 1999; Jackson, Morrow, Hill \& Dishman, 2004). In addition to promoting general health, physical activity also reduces the risks associated with coronary heart disease, colon cancer, high blood pressure and type 2diabetes (United States Department for Health and Human Services, 2006). Ganley and Sherman (2000) posited that regular physical activity is an important health maintenance strategy for children and adolescents (children reaching biological maturation development stage between the ages of 12 and 18 years), and research on the physical activity patterns of children is essential for the development and implementation of health promotion programmes. Sallis and Patrick (1994) distinguished two guidelines for physical activity, as determined during the International Consensus Conference on Physical Activity Guidelines for Adolescents held in San Diego in 1993. These guidelines, first, state that all adolescents should be physically active on a daily basis by participating in sport, games, walking, recreation, physical education or organised activities within the family, school or community. Secondly, adolescents should participate in approximately 20 minutes of moderate to high-intensity exercises, three or more times a week. In addition, they should strive to achieve participation of 20 minutes of low- to moderate-intensity (aerobic) exercise three times a week, and be active on all or most days of the week for at least 30 to 60 minutes (Sallis \& Patrick, 1994).

Evidence indicates a decline in the physical activity levels among adolescents during their teenage years up to 
early adulthood (Kemper et al., 2001; Leslie, Fotheringham, Owen \& Bauman, 2001). According to Kriska (2000), socioeconomic background plays an important role in adolescents' physical activity, and other studies indicate that children from rural communities participate less regularly in sport activities due to a lack of access, the cost of programmes and limited facilities (Nahas, Goldfine \& Collins, 2003). Public health researchers have shifted their attention from individual motivational theories of physical activity participation to the effects of community environments on health aspects such as physical activity. The research underscores significant differences regarding physical activity in various geographical areas and different demographic groups (Jones et al., 1998; Cooper \& Theriault, 2008).

\section{Theoretical Background}

The adverse impact of physical inactivity is widely known (Wendel-Vos et al., 2007), and constitutes a key health concern in many countries (Colditz, 1999; De Bruijn et al., 2006). With physical inactivity and its consequent chronic diseases as a dominant health risk, researchers have utilised the ecological approach to identify factors contributing to and constraining physical activity, especially in low-income neighbourhoods (Sealins, Sallis \& Frank, 2003). This theoretical approach suggests that normal motivational theory for physical activity does not account for the interaction between the individual and the physical environment. The ecological theory includes the built environment, for example, the effect that facility accessibility has on individuals and the physical activity decisions they make (Stokols, 1996). Accessibility refers to the closeness of facilities to children's homes, as well as how easily the facilities can be reached. Accessibility of facilities within a community influences people to walk or drive to work, children to walk or ride a bicycle to school, to frequently eat at fast-food restaurants, to spend family time in a neighbourhood park as well as to be physically active or inactive (Sallis \& Glanz, 2006). Conversely, it also exercises an active influence through the provision of accessible, appropriate, safe and engaging physical activity opportunities (Sallis \& Owen, 1996). Neighbourhoods that provide access to and are within the proximity of facilities, characterise elements encouraging physical activity (Boehmer et al., 2006).

\section{Facility Accessibility and Physical Activity}

In semi-urban areas where open areas to play near home are scarce and streets have a high traffic volume, which reduces young people's tendency to walk, children are likely to spend more time inactive and indoors (Timperio, 2004). Sedentary behaviour is a risk factor for obesity in young people and hypothesised associations between children's sedentary behaviour and the built environment need to be scrutinised (Saelens, 2003; Sallis \& Glanz, 2006). Governments ought to carefully plan semi-urban areas in the development phase and consider the barriers that accessibility of facilities may pose to the physical activity or inactivity of the young people within that community. Therefore, diverse opportunities should be provided for physical activity by ensuring justifiable distribution of parks and recreational facilities in towns and settlements (Sallis \& Glanz, 2006).

\subsection{Recreation facilities and accessibility}

The consistent link between built environmental factors such as the accessibility of facilities and physical activity remains a significant research area, which provides valuable information for government and developers in their endeavour to create and develop functional environments, thus promoting physical activity (Sallis \& Glanz, 2006). Research concerning young people and the effect that the accessibility of facilities has on their physical activity is scarce but valuable (Sallis \& Glanz, 2006). In this regard, the accessibility of specific stores, structures and activity centres has been demonstrated to affect children's weight through the influence on their eating habits and physical activity. Access to safe and convenient places to be physically active, combined with healthy and affordable food readily available, counters the negative effects of the built environment on children's general health (Sallis \& Glanz, 2006). Some studies have reported that children with free access to recreational facilities are more active compared to those without (Sallis, Prochaska \& Taylor, 2000). Sallis, Nader and Broyles (1993) similarly correlated access to facilities with higher physical activity levels among young people, while Norman (cited in Sallis \& Glanz, 2006) indicated a positive relationship between adolescent girls' physical activity and the proximity to recreational facilities. In Hoefers' (2002) study, adolescent boys reported that parks were most important for being physically active, while girls preferred commercial facilities. These factors should be considered since children should engage in a variety of activities on a regular basis and need appropriate and safe outdoor and neighbourhood facilities (Humpel, Neville \& Leslie, 2002). In low-income, semi-urban neighbourhoods, the tendency towards fewer parks, sports fields, clubs and trails augments the built-environment barriers young people face (Estabrooks, Lee \& Gyurcsik, 2004). Romero (2005) posited that adolescent physical activity participation was associated 
with higher socio-economic status (SES), where more facilities and safer areas with adult supervision were available to teenagers.

\subsection{Active commuting}

Urban arrangement and the community design encourage or discourage citizens from walking and/or cycling as a means of transport to and from work or school (Saelins, Sallis, Black \& Chen, 2003). Historically, small towns and urban areas were developed primarily with pedestrians in mind, and this led to the development of high-density residential areas. This traditional design was termed a "walkable" community (Sallis \& Glanz, 2006), with the necessary facilities within accessible reach. Recent studies indicated that residents of highly "walkable" neighbourhoods participated in physical activities one hour longer per week and were 2.4 times more likely to comply with the minimum physical activity recommendations (Sallis \& Glanz, 2006). In this regard, statistics show that a large percentage of children in rural areas walk to school and cover two to three km, or even up to six km to reach their school (Rowland et al., 2003; Wildschutt, 2005). Pupils who regularly commute are more active than those who are driven to school and enjoy positive physical effects such as enhanced body composition, fitness and health (Wildschutt, 2005). Therefore, active commuting contributes to the development of a healthy lifestyle for children and adolescents and should be taken into consideration when evaluating the accessibility of facilities in semi-urban areas.

A study by Dhurup and Grobler (2012) measured the physical activity levels and the impact of environmental factors on adults (18-65 years) from Bophelong, a semi-urban area in the Gauteng province of South Africa. In their findings, Dhurup and Grobler (2012) posited that less than 8 per cent of men and less than 6 per cent of woman participated in any recreational physical activity. Additionally, only 44 per cent of men and 30 per cent of women indicated that they regularly walked as a means of transport or for recreational and exercise purposes. This group of adults from the Bophelong area indicated that a lack of facilities and access to facilities were the second highest constraining factor to their physical activity levels (Dhurup \& Grobler, 2012) and that environmental factors such as street planning, neighbourhood surroundings and traffic safety also played an inhibitory part. Consequently, this group of adults showed severe health-related risks, whereby 32 per cent of men were classified as overweight and 39 per cent as obese. The women also showed similar results with 22 per cent classified as overweight and 68 per cent as obese (Dhurup \& Grobler, 2012). These findings necessitated a research focus on a younger population group in the same semi-urban area, in order to determine if the environmental barriers to physical activity and the prevalent physical inactivity trend of the adults in the Bophelong area are also present in youths from the same semi-urban area.

\section{Purpose of the Study}

The purpose of this study was to assess the accessibility of stores, schools, recreational and other important structures in Bophelong, a semi-urban area and the physical activity levels of high school pupils in the area.

\section{Methodology}

The study was conducted as part of a larger research project in Bophelong, a semi-urban, low-income residential township in Southern Gauteng. According to Statistics South Africa (2007), the average household in Bophelong has three persons. Slabbert and Sekampu (2009) also found that 66.3 per cent of the residents in this area are rated as poor, and the settlement has an unemployment rate of 62.2 per cent.

\subsection{Sample}

A total of 155 high school pupils from a high school in the Bophelong residential area in the Gauteng province comprised the sample from which data were collected for this study. There are three mid-sized high schools in the Bophelong area. The pupils were between 13 and 19 years of age, classifying them in the adolescence category. The relevant school authorities granted permission for the study to be conducted, but the school requested to remain anonymous. A random sample of pupils was drawn from the high school, considering gender for a fair distribution.

\subsection{Instrument}

A modified version of the Neighbourhood Environment Walkability Scale (NEWS) (Saelens et al., 2003), designed to 
obtain residents' perception of how neighbourhood characteristics positively or negatively affect their physical activity levels, was used to collect data for the study. The questionnaire contained questions on aspects such as stores, facilities and other important structures in the neighbourhood with regard to accessibility. Pupils had to indicate how long it took on average in minutes to walk to specific facilities within their community. They indicated this on a scale of 1-10 minutes, 11-30 minutes, 31+ minutes and lastly "do not know". In addition, general questions relating to the accessibility of facilities were answered on a four-point Likert scale that ranged from strongly agree to strongly disagree. Leisure-time physical activity was assessed with the Godin-Shepard Leisure-Time Exercise Questionnaire (Godin \& Shepard, 1985). The questionnaire allows the assessment of self-reported leisure-time physical activity. Pupils indicated that during a typical seven-day period how many times on average they are involved in different kinds of exercise for more than 15 minutes during their free time. The exercises were divided into the following categories: 1) Strenuous exercise: heart beating rapidly, referring to activities such as football, hockey, squash, running and netball. 2) Moderate exercise: not exhausting, including baseball, tennis, volleyball, badminton, easy swimming and dance. 3) Mild exercise: minimal effort, referring to activities such as yoga, archery, golf, easy walking and bowling (Godin, 2011). A section regarding the time spent walking per day was included as another physical activity category that correlates with the active commuting culture of the Bophelong community.

\subsection{Procedure}

University students from a Gauteng-based institution were trained in fieldwork aspects and the administration of questionnaires. Fieldworkers had to be proficient in English and an African language in order to explain the purpose of the study to the pupils. A senior researcher monitored students to ensure proper data collection. The high school pupils completed the questionnaire anonymously and voluntarily, and of the 168 responses, 155 were used. Thirteen of the completed questionnaires were discarded due to incomplete responses. Pupils were able to put questions to the fieldworkers if they did not understand the statements or questions and the fieldworkers assisted through explanation.

\section{Results}

\subsection{Demographic information}

A total number of 155 high school pupils voluntary and anonymously completed the questionnaires. From this group, 72 were males (47.1\%) and 83 were females (52.9\%), which provides a good equitable distribution. Of the 155 participants, 61.5 per cent were between the ages of 15 and 17 and 17.7 per cent were 13 to 14 years. Almost all of the pupils (98.6\%) were classified under the Black ethnic group, with 0.7 per cent Indian or Coloured, respectively.

Table 1: Descriptive statistics of participants

\begin{tabular}{lc}
\hline Demographic information & \\
\hline Gender & $47.1 \%$ \\
Male & $52.9 \%$ \\
Female & $4.6 \%$ \\
Age group & $13.1 \%$ \\
13 years & $20.3 \%$ \\
14 years & $20.9 \%$ \\
15 years & $20.3 \%$ \\
16 years & \\
17 years & \\
Ethnic group & $98.6 \%$ \\
African & $0.7 \%$ \\
Indian & $0.7 \%$ \\
Coloured &
\end{tabular}


Table 2: Accessibility of stores, facilities and other important structures

\begin{tabular}{lcccc}
\hline & \multicolumn{4}{c}{ Time it takes to walk * } \\
\hline Store, facility or structure & $1-10$ min & $11-30$ min & $31+$ min & Uncertain \\
\hline Convenience / small grocery store & 54.3 & 24.5 & 7.9 & 13.2 \\
Supermarket & 26 & 41.6 & 21.4 & 11 \\
Fruit / vegetable market & 42.8 & 32.9 & 16.4 & 7.9 \\
Clothing store & 6.4 & 31.8 & 36.4 & 25.3 \\
Library & 40.6 & 44.5 & 12.4 & 2.6 \\
Primary school & 47.3 & 41.2 & 17.6 & 4.1 \\
High school & 29.2 & 53.9 & 13 & 3.9 \\
Book store & 19.6 & 18.3 & 18.3 & 43.8 \\
Fast-food restaurant & 33.3 & 32 & 19.6 & 15 \\
Non-fast-food restaurant & 23.4 & 15.6 & 16.9 & 44.2 \\
Your school & 26.5 & 50.3 & 19.9 & 3.3 \\
Bus / taxi rank & 41.2 & 37.3 & 16.3 & 5.2 \\
Park & 20.1 & 35.1 & 29.9 & 14.9 \\
Recreation centre & 21.6 & 32.5 & 20.3 & 25.7 \\
Gym or fitness centre & 26 & 37.7 & 19.5 & 16.9 \\
\hline${ }^{*}$ Results are presented in percentages. Bold values indicate the highest percentage. & &
\end{tabular}

More than half the high school pupils (54.3\%) from the Bophelong area indicated a 1-10 minute walking distance, with 24.5 per cent indicating an 11-30 minutes walking distance to a convenience or small grocery store. The supermarket locations seemed to be scattered, since 41.6 per cent of the pupils indicated it took them between 11 and 30 minutes to walk to the nearest supermarket, 26 per cent indicated it took 1-10 minutes and 21.4 per cent that it took 31 minutes or more. The majority of pupils (42.8\%) walked 1-10 minutes to a fruit or vegetable market, with 32.9 per cent walking 1130 minutes and 16.4 per cent more than 31 minutes. More than a third of the pupils (36.4\%) indicated that it took them more than 31 minutes to walk to the nearest clothing store, while 31.8 per cent indicated that it took them 11-30 minutes. A quarter of the pupils (25.3\%) were uncertain as to how far the nearest clothing store was located. A total of 41.2 per cent and 37.3 per cent of pupils indicated being a walk of 1-10 minutes and a walk of 11-30 minutes respectively away from the nearest bus or taxi rank. A school-related facility such as a library was within 1-10 minutes walking distance for 40.6 per cent of the pupils and within 11-30 minutes for 44.5 per cent of the pupils.

Almost half the pupils (44.8\%) were uncertain as to how far the closest bookstore was, with 18.3 per cent indicating they had to walk either 11-30 minutes or more than 31 minutes. A total of 47.3 per cent of the pupils indicated they could walk 1-10 minutes to the nearest primary school, and 41.2 per cent could walk 11-30 minutes. More than half the pupils (53.9\%) walked to the nearest high school within 11-30 minutes, 29.2 per cent within 1-10 minutes and 13 per cent had to walk more than 31 minutes. Half the students (50.3\%) indicated that it took them 11-30 minutes to walk to their own school. A quarter of the pupils (26.5\%) walked 1-10 minutes and 19.9 per cent walked longer than 30 minutes to their own school. Fast-food restaurants were in close proximity to the pupils' homes, with 33.3 per cent indicating that it was a 1-10 minutes' walk and 32 per cent an 11-30 minutes' walk away. Almost half the pupils (44.2\%) were uncertain of how long it took them to walk to the nearest non-fast-food restaurant, and 23.4 per cent indicated a 1-10 minutes' walk. Facilities relating to physical activity such as parks, recreation centres and gyms or fitness centres seemed further away for the majority of pupils. More than a third of the pupils (35.1\%) indicated that a park was an 11-30 minutes' walk, 29.9 per cent that it was more than 31 minutes' walk and only 20.1 per cent a 1-10 minutes' walk away. For the majority of pupils a recreation centre was further from home, with 32.5 per cent indicating they had to walk 11-30 minutes and 20.3 per cent had to walk more than 31 minutes to the nearest recreation centre. Less than a quarter of the pupils (21.6\%) could walk 1-10 minutes to the nearest recreation centre. For 37.7 per cent of the pupils a gym or fitness facility was an 11-30 minutes' walk from their home, for 26 per cent it was a 1-10 minutes' walk, and for 19.5 per cent it was more than a 31 minutes' walk. 
Table 3: Access to facilities

\begin{tabular}{|c|c|c|c|c|c|c|c|c|}
\hline \multirow[t]{2}{*}{ Among the residences in your neighbourhood... } & \multicolumn{2}{|c|}{ Strongly disagree } & \multicolumn{2}{|c|}{ Disagree } & \multicolumn{2}{|c|}{ Agree } & \multicolumn{2}{|c|}{ Strongly agree } \\
\hline & $\mathrm{n}$ & $\%$ & n & $\%$ & $\mathbf{n}$ & $\%$ & $\mathrm{n}$ & $\%$ \\
\hline $\begin{array}{l}\text { I can do most of my shopping at stores within a 10-15 min walk from } \\
\text { my home }\end{array}$ & 51 & 33.1 & 44 & 28.6 & 42 & 27.3 & 17 & 11 \\
\hline There are many places to go within a $10-15$ min walk from my home & 24 & 15.6 & 28 & 18.2 & 60 & 39 & 42 & 27.3 \\
\hline It is easy to walk to a bus/taxi rank & 12 & 7.8 & 17 & 11 & 67 & 43.5 & 58 & 37.7 \\
\hline $\begin{array}{l}\text { There are many hillsides in my neighbourhood that limit the number of } \\
\text { routes to walk }\end{array}$ & 53 & 34.4 & 55 & 35.7 & 35 & 22.7 & 11 & 7.1 \\
\hline
\end{tabular}

Bold indicates the highest percentage

Almost a third of the pupils (33.1\%) strongly disagreed that they could do most of their shopping within a 10-15 minutes' walk from their home. A total of 39 responded that there were many places for them to go within a 10-15 minute walk, and 43.7 per cent indicated that they perceived it to be easy to walk to a bus or taxi rank. Just over a third (35.7\%) of the pupils indicated that the neighbourhood was fairly flat and that hills were not present to obstruct the number of routes to walk.

Table 4: Percentage of pupils participating in strenuous, moderate, mild and walking exercise

\begin{tabular}{lcccccccc}
\hline Day of the week & Sunday & Monday & Tuesday & Wednesday & Thursday & Friday & Saturday & Average \\
\hline Activity & $\%$ & $\%$ & $\%$ & $\%$ & $\%$ & $\%$ & $\%$ & $\%$ \\
\hline Strenuous exercise & 32.9 & 51 & 43.9 & 45.8 & 40.6 & 42.6 & 47.1 & 43 \\
Moderate exercise & 31.6 & 43.9 & 40.6 & 43.9 & 39.4 & 42.6 & 32.6 & 39.2 \\
Mild exercise & 31 & 34.2 & 22.6 & 27.1 & 23.9 & 26.5 & 29 & 27.7 \\
Walking & 49 & 82.6 & 78.7 & 80.6 & 79.4 & $\mathbf{8 3 . 2}$ & 43.2 & 71 \\
\hline
\end{tabular}

Bold indicates the highest percentage

Of the 155 participants, less than half the pupils (43\%) on average indicated that they participated in strenuous activities such as football, hockey, squash, running and netball on a daily basis for more than 15 minutes. The highest percentage (51\%) participated in strenuous activities on Mondays, followed by 47.1 per cent on Saturdays, and then Wednesdays (45.8\%), Tuesdays (43.9\%) and Thursdays (42.6\%). An average of 39.2 per cent of the participants reported participation in moderate exercise, including easy cycling, volleyball and easy swimming. Mondays and Wednesday (both 43.9\%) and Fridays (42.6\%) were reported as the days with the highest moderate activity participation, with Saturdays and Sundays as the lowest (32.6\% and $31.6 \%$ respectively). Less than a third of the pupils $(27.7 \%)$ on average acknowledged engaging daily in mild exercises requiring minimal effort such as yoga, fishing, bowling, golf and archery. The highest percentage of pupils (34.2\%) engaged in mild exercise on a Monday, with levels ranging from 31 per cent to 22.6 per cent of pupils being mildly active on the other days. Walking from home and from place to place were indicated on average by 71 per cent as a daily activity, with the lowest walking activity by pupils being reported on Saturdays (43.2\%) and Sundays (49\%). On Fridays, 83.2 per cent of the pupils walked for more than 15 minutes, on Mondays 82.6 per cent and on Wednesdays 80.6 per cent.

\section{Discussion}

\subsection{Accessibility of facilities}

High school pupils from low-income communities demonstrate less participation in sport and physical activities mainly due to a lack of access to sport and recreational facilities (Coetzee, 2003; Jackson et al., 2004). Only a small portion of the pupils were a one to ten minutes' walk from a park, recreation centre, gym or fitness centre and more than a third had to walk more than 30 minutes to reach a facility where they could engage in physical activity. This distance to facilities correlates with findings from Nahas et al. (2003) as being a barrier to physical activity for adolescents from a low-income community. An additional barrier for this group includes the cost of supervised programmes and gym or facility fees (Nahas et al., 2003), reducing the likelihood of consistent use of facilities for physical activity and health purposes. Food shopping facilities such as a small grocery store, supermarket and a fruit or vegetable market were not in close proximity, as the majority of pupils had to commute 31 minutes or more to the nearest supermarket. Similarly, clothing stores 
seemed to be located far away from their homes and pupils were forced to walk considerable distances for additional shopping needs. It is evident that this group of high school pupils need to walk excessive distances to buy everyday necessities. Completing everyday life activities such as walking to and from the store requires additional energy, which increases energy expenditure (Prista, Maia \& Marques et al., 1997). Consequently, adolescents from low SES show higher levels of physical activities mainly due to more time spent walking within the neighbourhood, whereas children from higher SES tend to be driven by car to where they want to be (Tudor-Locke, Ainsworth \& Popkin, 2001). Accessibility of fast-food restaurants is alarmingly high for this group, with the pupils demonstrating the inclination not to access non-fast-food restaurants. Unhealthy fast-food restaurants were more readily accessible to the pupils. Sallis and Glanz (2006) related the deterioration of the healthy eating habits of adolescents to the easy accessibility of fast-food restaurants, which also led to a decline in physical activity. People with greater access to health foods than to fast food are more likely to eat healthy food and this may help avoid negative consequences such as obesity (Sallis \& Glanz, 2006).

A bus or taxi rank was in relatively close proximity, causing pupils to make use of such transport for various reasons to and from school, reducing their physical activity levels (Tudor-Locke et al., 2001).

\subsection{Active commuting}

The majority of pupils from this high school in the semi-urban area of Bophelong walked far distances to their school. The same tendency is evident in numerous parts of the world in low socio-economic communities where children are forced to actively commute on a daily basis to and from school (Prista et al., 1997; Cooper, Page, Foster \& Qahwaji, 2003; Wildschutt, 2005). Even though active commuting contributes to the overall physical activity levels of pupils (Rowland et al., 2003), it is alarming that this type of exercise constitutes the primary activities of pupils within this semi-urban area high school. This further correlates with findings by Prista et al. (1997), namely that adolescents from a low SES have sufficient levels of low-impact physical activity through active commuting and in performing family-related tasks. Pupils have reported fetching younger siblings from day-care centres or primary schools from a low SES as a daily activity (Lennox, Pienaar \& Coetzee, 2007) which contributes to overall daily walking activity. It is unfortunate that this type of low-intensity exercise is the primary form of physical activity for the high school pupils and indicates a lack of facilities, recreational programmes and additional opportunities to engage in enjoyable physical developmental events. Fortunately, the relatively flat neighbourhood surroundings are beneficial to walking far distances, which encourage active commuting and the performance of family-related chores.

\subsection{Physical activity}

The guidelines as stated at the International Consensus Conference on Physical Activity for Adolescents in 1993 (Sallis \& Patrick, 1994) indicate that adolescents should be active daily through sport, games, walking as means of transport, recreation, physical education or organised activities within the family, school or community. This study indicates that more than half the high school pupils do not comply with these guidelines, especially with regard to recreational activities, activities in the community and games. Pupils mainly indicated physical activity as a means of transport and less than half of them on average participated in sport or physical education at school, since the strenuous exercises pupils reported to engage in may be attributed to sports activities such as soccer and netball at school (Lennox et al., 2003).

Results indicate that pupils from the high school in the semi-urban area on average do not adhere to the second guideline for physical activity, as set out in San Diego in 1993 (Sallis \& Patrick, 1994). The second guideline encourages adolescents to participate in approximately 20 minutes of moderate to high-intensity exercises, for three or more sessions per week. The participation in moderate exercise such as easy cycling, volleyball and dancing was also alarmingly low, with the minority of pupils engaging in this form of physical activity. This tendency also decreased during the weekend, which is indicative of participation in activities presented mainly at school during weekdays. Pupils demonstrated the lowest rate of mild exercise participation in activities such as yoga, easy walking, archery, bowling and golf. These recreational activities require either special equipment or facilities - both of which are lacking in this low socio-economic area. The second guideline prescribing an additional 20 minutes of low- to mild-intensity activity three times per week is also not achieved.

Evidently, pupils either engage in physical activity through active commuting (walking long distances to and from school and stores, and performing family responsibilities such as picking up younger siblings from different schools), or a few participate in school sports activities. It is clear that pupils from this high school in the semi-urban area Bophelong, are largely inactive and in need of access to physical activity centres, coupled with activity programmes and guidance in 
adopting physically active lifestyles. The lack of facilities, access to physical activity facilities and programmes within the community set-up could be an influential factor in this tendency and should be addressed by local government. This continuous lack in appropriate, regular physical activity is regarded as a contributing factor to health-related conditions such as coronary heart disease, high blood pressure, type 2-diabetes and obesity, and pupils from this semi-urban high school may be in a predisposition towards such health-related conditions in future. In Dhurup and Groblers' (2012) study, the majority of adults from the Bophelong area were classified as overweight and obese, and their extreme low physical activity levels may have been a contributing factor to their health condition. Consequently, the high school pupils from this semi-urban area may follow the same inactive and overweight route.

\section{Limitations of Study}

The study focused on the singular aspect regarding accessibility to stores, facilities and important structures within a semi-urban community relating to the physical activity of high school pupils. Findings of this study highlight the barriers that accessibility of facilities may pose to physical activity, as well as the lack thereof in a semi-urban area. Generalisation of results should be done with caution due to the small sample size.

\section{Conclusion}

The study of an environmental factor such as accessibility of facilities within a semi-urban community on the physical activity of high school pupils rendered valuable insights. Pupils engage in adequate levels of low-intensity (walking) physical activity on a daily basis through active commuting to and from school. In addition, the relatively long distances pupils need to cover to reach facilities such as grocery and clothing stores contribute positively to the recommended daily physical activity levels for that particular activity. This is alarming, since this type of activity can be seen as essential for the everyday life of these pupils and not as a part of their leisure-time exercise. If these pupils were not forced to commute to school or walk long distances to reach shops, they would be largely inactive. Apart from walking, less than half the pupils engage in school sport activities as a secondary mode of physical activity. The lack of facilities and access to them within the community, external to the school set-up is evident. Pupils are discouraged from participation in a variety of moderate and mild exercises because of the lack of and access to physical activity facilities.

\section{References}

Boehmer, T. K., Hoehner, C. M., Wyrwich, K. W., Ramirez, L. K. B., \& Brownson, R. C. (2006). Correspondence between perceived and observed measures of neighbourhood environmental supports for physical activity. Journal of Physical Activity and Health, 3, 2236.

Coetzee, Z. (2003). Reasons and barriers to sport participation among high school learners in the Potchefstroom district. (Unpublished Thesis - MA). Potchefstroom University: PU for CHE.

Colditz, G. A. (1999). Economic cost of obesity and inactivity. Medical \& Science in Sports \& Exercise, 31(11), 663-667.

Cooper, A. R., Page, A. S., Foster, L. J., \& Qahwaji, D. (2003). Commuting to school: are children who walk more physically active? American Journal of Preventative Medicine, 25(4), 273-276.

Cooper, N., \& Theriault, D. (2008). Environmental correlates of physical activity: implications for campus recreation practitioners. Recreational Sports Journal, 32, 97-195.

De Bruijn, G. J., Kremers, S. P. J., Lenavelt-Mulders, G., de Vries, H., van Mechelen, W., \& Brug, J. (2006). Modelling individual and physical environmental factors with adolescent physical activity. American Journal of Preventative Medicine, 30(6), 507-512.

Dhurup, M., \& Grobler, W. C. J. (2012). The built environment and physical activity participation in a semi-urban area in Southern Gauteng: physical activity and health. African Journal of Physical, Health, Education, Recreation and Dance: Contemporary issue in sport in the 21st Century: Supplemental, 1, 414-430.

Estabrooks, P. A., Lee, R. E., \& Gyurcsik, N. C. (2004). Resources for physical activity participation: Does availability and accessibility differ by neighbourhood socioeconomic status? Annals of Behavioral Medicine, 25, 100-104.

Ganley, T., \& Sherman, C. (2000). Exercise and children's health. The Physician and Sports Medicine, 28(2), 85-92.

Godin, G. (2011). Commentary: The Godin-Shepard leisure-time physical activity questionnaire. Health and Fitness Journal of Canada, 4(1), 18-22.

Godin, G. R., \& Shepard, R. J. (1985). A simple method to assess exercise behaviour in the community. Canadian Journal of Applied Sport Science, 10, 141-146.

Hoefer, W. R. (2002). Parental provision of transportation for adolescent physical activity. American Journal of Preventive Medicine, 21 , 48-51.

Humpel, N., Neville, O. N., \& Leslie, E. (2002). Environmental factors associated with adults' participation in physical activity: A review. American Journal of Preventive Medicine, (2)2, 188-199. 
Jackson, A. W., Morrow, J. R., Hill, D. W., \& Dishman, R. K. (2004). Physical activity for health and fitness: Updated edition. Champaign, III.: Human Kinetics.

Jones, D. A., Ainsworth, B. E., Croft, J. B., Macera, C. A., Lloyd, E. E., \& Yusuf, H. R. (1998). Moderate leisure-time physical activity: Who is meeting the public health recommendations? National cross-sectional study. Archives of Family Medicine, 7, 285-289.

Kemper, H. C. G., Twisk, J. W. R., Koppes, L. L. J., Van Mechelen, W., \& Post, G. B. (2001). A 15-year physical activity pattern is positively related to aerobic fitness in young males and females (13-27 years). European Journal of Applied Physiology, 84, 395402.

Kriska, A. (2000). Ethnic and cultural issues in assessing physical activity. Research quarterly for exercise and sport, 71(2), 47-53.

Lennox, A., Pienaar, A. E., \& Coetzee, M. (2007). Barriers, motivators, sport participation and perceptions about physical activity among adolescents living in semi-urban surroundings. African Journal of Physical, Health, Education, Recreation and Dance, September (Supplement), 289-303.

Leslie, E., Fotheringham, K. J., Owen, N., \& Bauman, A. (2001). Age-related differences in physical activity levels of young adults. Medicine \& Science in Sport \& Exercise, 33(2), 255-258).

Nahas, M. V., Goldfine, B., \& Collins, M. A. (2003). Determinants of physical activity in adolescents and youth adults: the basis for high school and college physical education to promote active lifestyles. Physical Educator, 60(1), 42-56.

Pate, R. R., Trost, S. G., Dowda, M., Ott, A. E., Ward, D. S., Saunders, R., \& Felton, G. (1999). Tracking of physical activity, physical inactivity and health-related physical fitness in rural youth. Paediatric Exercise Science, 11, 364-376.

Prista, A., Maia, J. A. R., \& Marques, A. T. (1997). The relationship between physical activity, socio-economic status and physical fitness of 8-15 year old youth from Mozambique. American Journal of Human Biology, 9, 449-457.

Romero, A. J. (2005). Low-income neighbourhood barriers and resources for adolescents' physical activity. Journal of Adolescent Health, 36, 253-259.

Rowland, D., Diguiseppi, C., Gross, M., Afolabi, E., Roberts, I. (2003). Randomised controlled trail of site specific advice on school travel patterns. Archives of Disease in Childhood, 88(8), 8-11.

Saelens, B. E. (2003). Helping individuals reduce sedentary behaviour in obesity: Etiology, assessment, treatment and prevention (pp. 217-38). Champaign, III.: Human Kinetics.

Saelins, B. E., Sallis, J. F., \& Frank, L. D. (2003). Environmental correlates of walking and cycling: Findings from the transportation, urban design and planning literatures. Annals of Behavioural Medicine, 25, 80-91.

Saelins, B. E., Sallis, J. F., Black, B. A., \& Chen, D. (2003). Neighbourhood based differences in physical activity: an environment scale evaluation. American Journal of Public Health, 93(9), 1552-1558.

Sallis, J. F., \& Glanz, K. (2006). The role of built environments in physical activity, eating and obesity in childhood. Future of Children, 16(1), 89-108.

Sallis, J. F., \& Owen, N. (1996). Ecological models. In K. Glanz, F. M. Lewis \& B. K. Rimer (Eds.), Health behaviour and health education: Theory, research, and practice (2nd ed.). (pp. 403-424). San Francisco: Jossey-Bass.

Sallis, J. F., Nader, P. R., \& Broyles, S. L. (1993). Correlates of physical activity at home in Mexican-American and Anglo-American preschool children. Health Psychology, 12, 390-398.

Sallis, J. F., \& Patrick, K. (1994). Physical activity guidelines for adolescents: Consensus statement. Paediatric Exercise Science, 6, 302314.

Sallis, J. F., Prochaska, J. J., \& Taylor, W. C. (2000). A review of correlates of physical activity of children and adolescents. Medicine and Science in Sports and Exercise, 32, 963-975.

Slabbert, T. J. C., \& Sekampu, T. J. (2009). Bophelong: A socio-economic and environmental analysis. Research report no. 22. Vanderbijlpark: Vaal Research Group.

Statistics South Africa. (2007). Community survey 2007. Statistical release P0301. Pretoria: Government Printers.

Stokols, D. (1996). Translating social ecological theory into guidelines for community health promotion. American Journal of Health Promotion, 10(4), 282-298.

Timperio, A. (2004). Perceptions about the local neighborhood and walking and cycling among children. Preventive Medicine, 38, $39-47$.

Tudor-Locke, C., Ainsworth, B. E., \& Popkin, B. M. (2001). Active commuting to school: An

overlooked source of children's physical activity? Sports Medicine, 31, 309-313.

United States Department for Health and Human Services. (2006). [Online] Available: http://www.hhs.gov/news/factsheet/ physactive.html (April 01, 2014).

Wendel-Vos, W., Droomers, M., Kremers, J., Brug, J., \& van Lente, F. (2007). Potential environmental determinants of physical activity in adults: A systematic review. Obesity Reviews, 8, 425-440.

Wildschutt, P.J. (2005). The effect of accumulative physical activity on the fitness and health status of rural school children. Unpublished Masters dissertation. Cape Town: University of the Western Cape. 